\title{
Determination of the wind pressure distribution on the facade of the triangularly shaped high-rise building structure
}

\author{
Norbert Jendzelovsky ${ }^{1,}{ }^{*}$, Roland Antal $^{1}$ and Lenka Konecna ${ }^{1}$ \\ ${ }^{1}$ STU in Bratislava, Faculty of Civil Engineering, Radlinskeho 11, Bratislava 810 05, Slovakia
}

\begin{abstract}
Methods for determination of the wind pressure distribution on the facade of the atypically shaped high-rise building structure will be shown. The standard Eurocode 1 [1] does not mention recommendations for calculation of wind pressure distribution on the facade for the most cases of buildings having an irregular cross-section. Analysed object has a shape of the equilateral triangle. For the determination of the pressure distribution two methods were used. Experimental analysis was carried out in the boundary layer wind tunnel and second approach was performed by numerical simulation of wind flow using computational fluid dynamics (CFD) software based on the finite volume method. Both methods used scaled model of the structure. For the wind tunnel experiment, 16 points of interests around an object were monitored in steady wind flow and from those points, results of external pressure coefficients from 2 directions of wind flow were obtained. In conclusion comparison of results of both methods will be shown.
\end{abstract}

\section{Analysis of the wind pressure distribution on the equilateral triangle}

High-rise structure was considered having a shape of an equilateral triangle (Fig. 1).
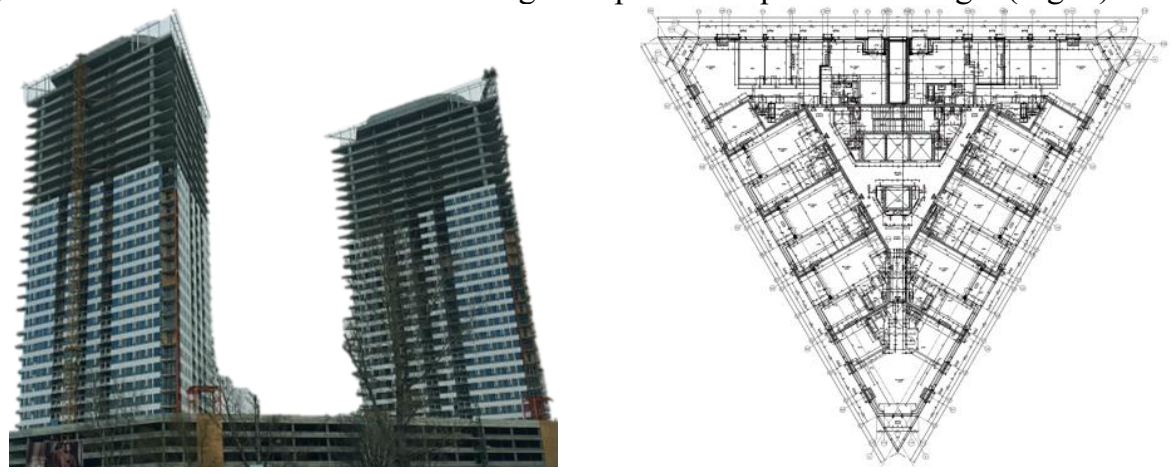

Fig. 1. Object of Panorama city buildings (Bratislava, Slovakia) and floor plan.

${ }^{*}$ Corresponding author: norbert.jendzelovsky@stuba.sk 
Analysis of the wind pressure distribution was performed on the triangular cross-section of the scaled model. Length of the edge of the real size building is $51.34 \mathrm{~m}$. Experimental and numerical model was created in scale 1:171.

\subsection{Experimental study of pressure distribution in the boundary layer wind tunnel}

Model for wind tunnel tests was created as a scaled simplification of mentioned high-rise building (Fig. 2a). Scale of this experimental model compared to the size of the real building is $1: 172$. Scale of the analysed object was set in regard to size of wind tunnel and previous measurements related to experimental investigations of an air flow and influences of walls and ceilings in the wind tunnel $[2,3]$.

Before positioning of sampling points, where wind pressure was measured, preliminary CFD simulations were done. Results of these numerical simulations gave us insight of how the pressure is distributed around an object, and where sampling points for experimental measurements should be positioned. 16 sampling points were created irregularly around the model (Fig. 2b). At these particular points pressure was measured by digital pressure scanner DSA 3217 Scanivalve from two directions of wind flow.
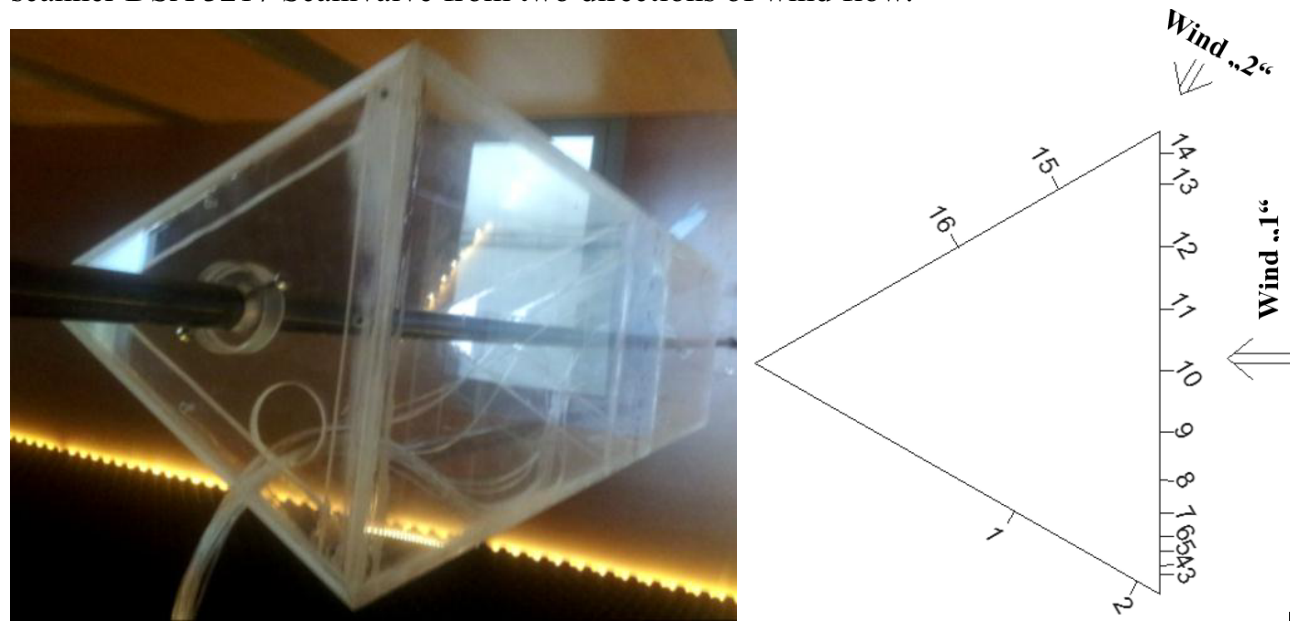

Fig. 2. a) Scaled model in wind tunnel and b) positioning of 16 sampling points.

For experimental measurements, opened, under-pressure, boundary layer wind tunnel was used. Tunnel has length of $26.3 \mathrm{~m}$ and its cross section has shape of rectangle with dimensions $2.6 \mathrm{~m} \times 1.6 \mathrm{~m}$. Tunnel consists of two main sections - front and rear space. Wind speed is adjustable in a range of $0.2-32 \mathrm{~m} / \mathrm{s}$. For turbulent flows, where turbulence of wind flow is required, rear space is used. For our purposes, front space of wind tunnel was used. Frontal area is used, when steady wind flow is required. Therefore, analysed object was tested in constant wind speed, without any significant turbulences. Properties of air measured on the day of tests are shown in Table 1.

Table 1. Boundary conditions and properties of air in the wind tunnel at the day of measurements.

\begin{tabular}{|c|c|c|c|}
\hline $\begin{array}{c}\text { Wind speed } \\
{[\mathrm{m} / \mathrm{s}]}\end{array}$ & $\begin{array}{c}\text { Temperature of air } \\
{\left[{ }^{\circ} \mathrm{C}\right]}\end{array}$ & $\begin{array}{c}\text { Atmospheric pressure } \\
{[\mathrm{Pa}]}\end{array}$ & $\begin{array}{c}\text { Density of air } \\
{\left[\mathrm{kg} / \mathrm{m}^{3}\right]}\end{array}$ \\
\hline 12.08 & 22.8 & 99870 & 1.170502 \\
\hline
\end{tabular}


Pressure was measured in 16 sampling point from both directions of wind flow twice, therefore averaged values of measured pressure were calculated. For better illustration, measured pressures were converted to external pressure coefficient, which is a dimensionless variable calculated by formula (1). Pressure coefficient demonstrates, how the pressure is distributed around an object depending on the direction of wind flow.

$$
C_{p}=\frac{p-p_{\infty}}{\frac{1}{2} \cdot \rho_{\infty} \cdot v_{\infty}^{2}}
$$

Where $p$ is the pressure at the point at which pressure coefficient is being evaluated in $[\mathrm{Pa}]$,

$p_{\infty}$ is the pressure in the free stream in $[\mathrm{Pa}]$,

$\rho_{\infty}$ is the free stream fluid density in $[\mathrm{kg} / \mathrm{m} 3]$,

$v_{\infty}$ is the free stream velocity of the fluid in $[\mathrm{m} / \mathrm{s}]$.

In the following figure (Fig. 3) distribution of wind pressure around an object in the dimensionless external pressure coefficient for both directions of wind flow is shown.
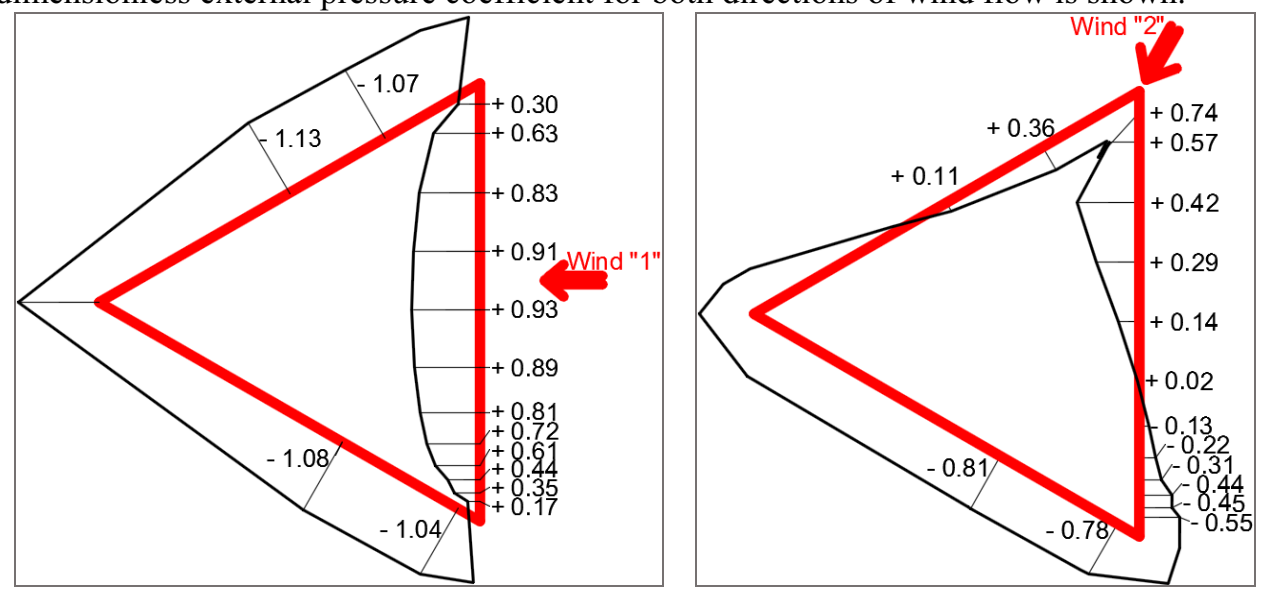

Fig. 3. External pressure coefficient $C p[-]$ for both analysed wind flow directions.

\subsection{Computational fluid dynamic simulation of wind flow}

Computational model was analysed by software based on finite volume method. Additional software systems for geometry, mesh and results were used. Size of analysed boundaries for an air flow simulation were created as follows (Fig. 4): Length of boundary is $9.4 \mathrm{~m}$, width of boundary is $6.6 \mathrm{~m}$ and height of boundary is $5.6 \mathrm{~m}$.

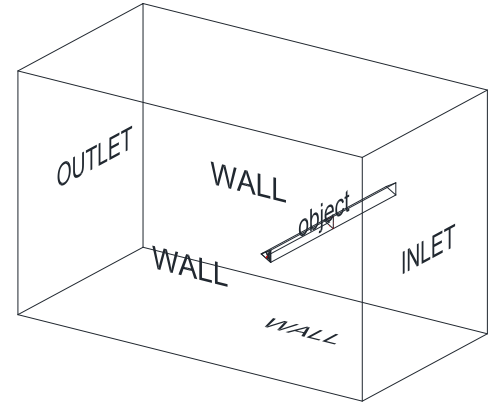

Fig. 4. Analysed boundaries for CFD simulation. 
Mesh generator was used to create following mesh: Element type was set as Hexahedra, which were refined closer to the object of interest. Near analysed model, first boundary layer was created $0.01 \mathrm{~mm}$ from object edge. 40 other fine mesh layers were created gradually around an object with growth rate 1.2 (Fig. 5). Largest elements with size of 400 $\mathrm{mm}$ were created in the remote surroundings where turbulences of air does not significantly affect flow around an object.

For computational simulations, parameters were set according to data measured during wind tunnel tests. Input parameters used for CFD simulation are listed in (Table 1) Parameters and properties, which were not measured (roughness of object, small turbulence of wind flow etc.) were set simplistically by estimation.

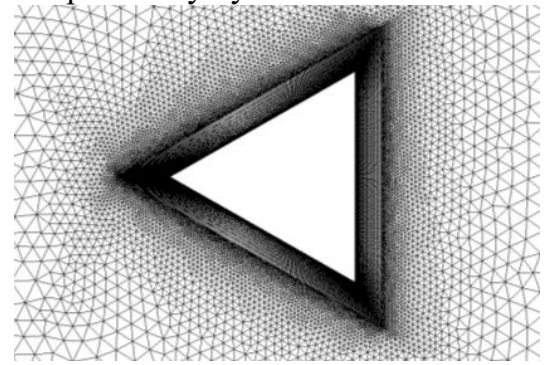

Fig. 5. Hexahedral mesh near object.

Flow simulation was carried out by CFD software module. Selected module calculates variables by finite volume method based on elements - EbFVM, with a cell vertex formulation.

For the given flow simulation, shear stress transport (SST) mathematical model was selected. It is the two-equation eddy-viscosity model, which combines two mostly used k- $\omega$ and $k-\varepsilon$ models. The formulation of the SST model is based on wind tunnel experiments and it attempts to predict solutions to typical engineering problems. Equations used in $k-\omega$ model work best for near wall treatment through the viscous sub-layers. In the free stream flow, where near wall treatment is not essential, SST model automatically switches to k- $\varepsilon$ model and hence, it avoids common $k-\omega$ problem, which is too sensitive to the inlet free-stream turbulence properties. Other information about mentioned mathematical models can be found in $[4,5,6]$.

Process of calculation was iterative, therefore residuals, imbalances and pressures were monitored until satisfying results were reached. After 90 iterations, results of pressure didn't change significantly and iteration process was complete and solution was found.

Results of pressure coefficients for both wind flows are shown in (Fig. 6). For graphical representation wind flows from left to right in both cases.

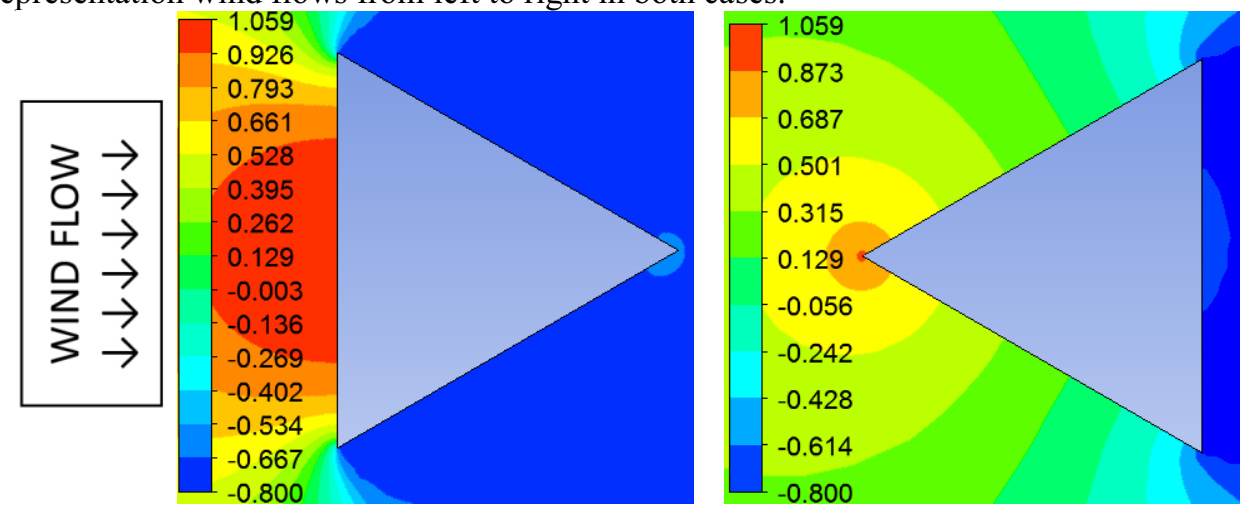

Fig. 6. Results of calculated pressure coefficient $C p[-]$ for both wind flows. 


\subsection{Comparison of wind tunnel measurements with CFD simulation}

Demonstration of 2 methods used for calculations of wind pressure distribution was a matter of interest here. Results of external pressure coefficient measured in wind tunnel are compared with CFD simulation.

Comparison of results are shown in figures (Fig. 7) and (Fig. 8), where values of calculated pressure coefficient in sampling points are compared for both methods and both wind flow directions. On the horizontal axis, numbers of sampling points are shown. On the vertical axis, values of calculated external pressure coefficient are shown.

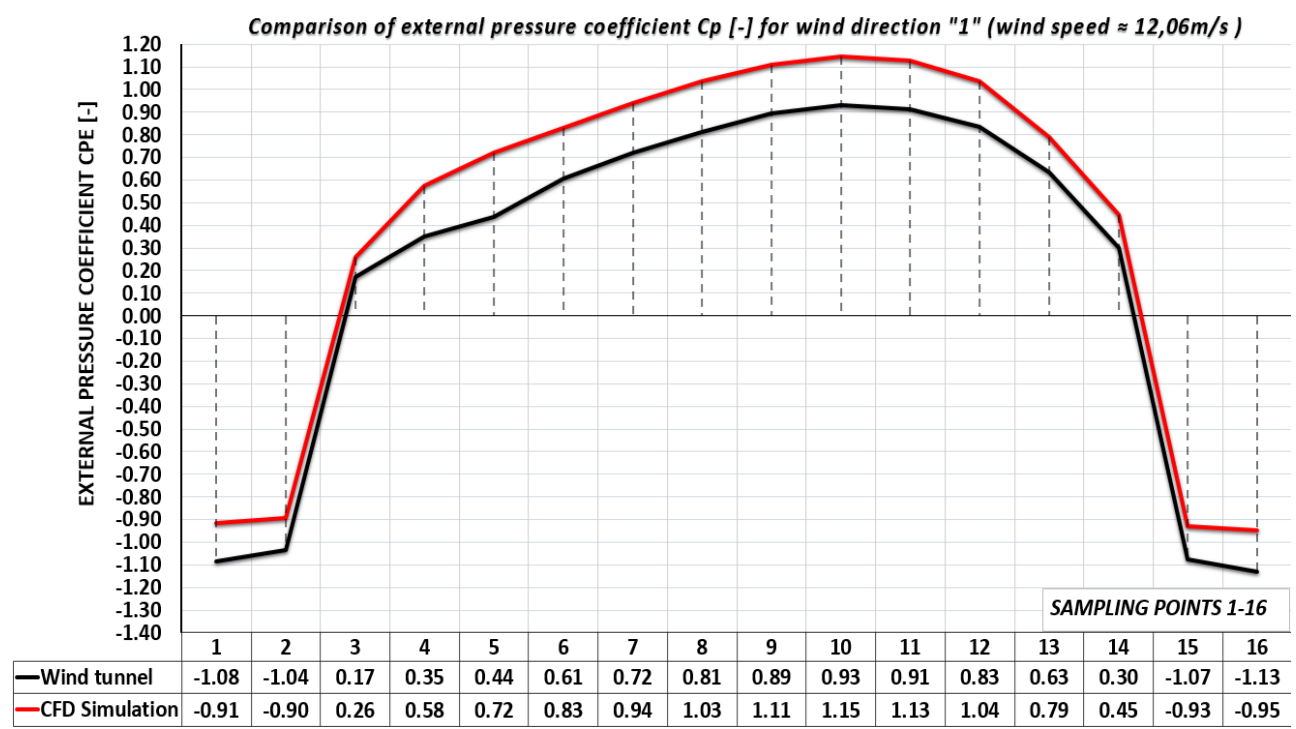

Fig. 7. Comparison of calculated pressure coefficient $C p[-]$ for wind flow "1".

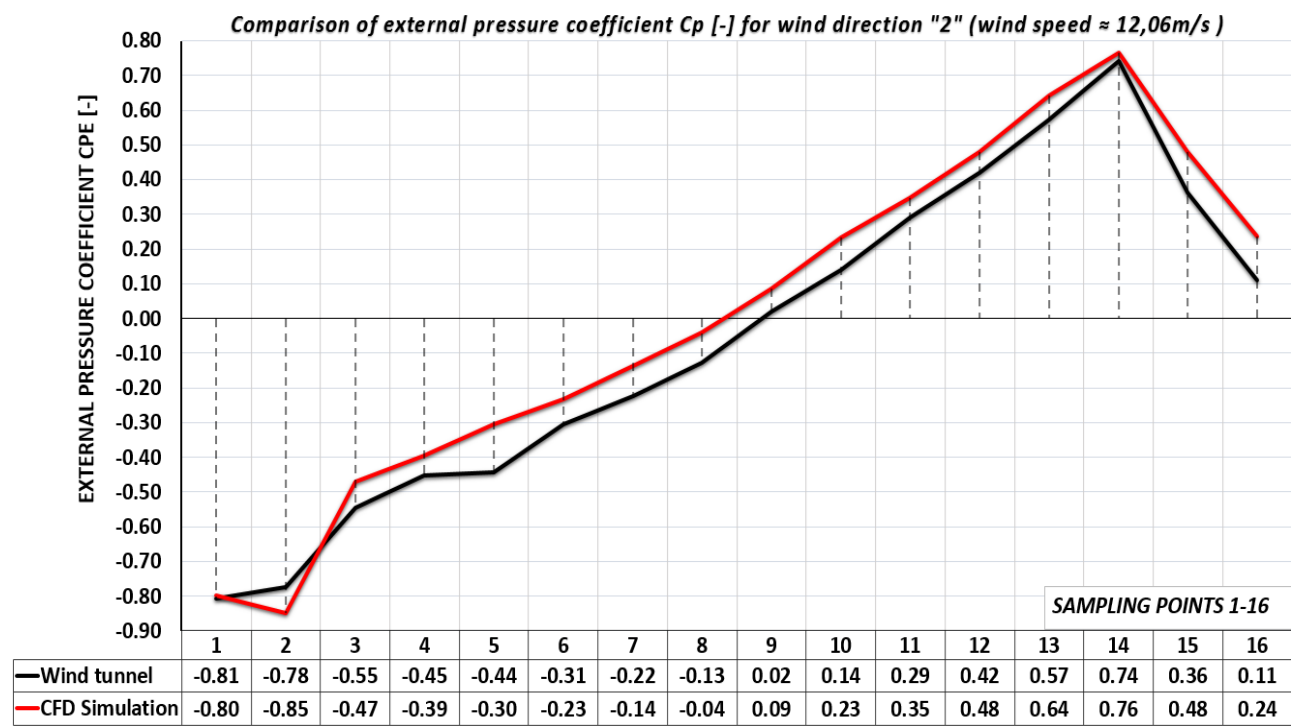

Fig. 8. Comparison of calculated pressure coefficient $C p[-]$ for wind flow " 2 ".

As we can see in both figures (Fig. 7) and (Fig. 8), results measured in the wind tunnel are slightly different to those, which were calculated by CFD simulation. 
As a conclusion, it can be said, that both methods are capable to calculate variables needed to design a high-rise building structure. CFD simulation where SST mathematical model was used, proved, that it is very good and relatively accurate tool for calculation of many variables, even for those, which cannot be measured directly in the wind tunnel.

Differences between numerical simulation and experiment could be caused by many factors. Main factors responsible for differences in similar cases are: a) small differences between geometry of wind tunnel model and the model used in computational flow simulation - just a small difference in geometry in that scale could cause abnormality in results; b) position of model in wind tunnel during air flow - even very small rotation or movement of model can cause different results compared to "ideal" conditions simulated by CFD software; c) Boundary size, mesh size and boundary conditions set in CFD software changes in boundary size, mesh size, number and size of near wall layers and of course changes of properties of air, wind speed, turbulence intensity, will change results significantly.

These days, cooperation between wind tunnel tests with addition of CFD simulation is the best way, how to analyse wind effects on irregular shaped buildings and determine wind load for unusual structures.

This paper was supported by Grant Agency VEGA of Slovak Republic, project No. 1/0544/15.

\section{References}

1. EN 1991-1-4, Eurocode 1: Actions on structures-Part 1-4: General actions-Wind actions, (2007)

2. O. Hubová, P. Lobotka, Scientific-Technical Journal 1, 2, (2014)

3. M. Jirsák, Studie budov a konstrukci ve vetrných tunelech, (ČKAIT, Praha, 2009)

4. F. R. Menter, AIAA Journal, 32, 1598, (1994)

5. J. D. Anderson, Computational Fluid Dynamics: The Basics with Applications. (McGraw-Hill Inc., 1995)

6. T. J. Chung, Computational Fluid Dynamics - Second Edition (Cambridge University Press, New York, 2010) 